\title{
Clinical Reasoning: Bilateral ptosis, dysphagia, and progressive weakness in a patient of French-Canadian background
}

Pritikanta Paul, MD, Reem Alhammad, MD, and Elie Naddaf, MD

Neurology ${ }^{\circledR}$ 2020;95:933-938. doi:10.1212/WNL.0000000000010613
Correspondence

Dr. Naddaf

Naddaf.Elie@mayo.edu

\section{Section 1}

A 40-year-old man presented with slowly progressive weakness and eyelid droopiness. His symptoms began in his early 30s as increased fatigue with exertion. In his mid 30s, he developed droopy eyelids without double vision. About 3 years before presentation, he started having progressive difficulty swallowing, initially with solid food but later with both solid and liquid consistencies. He also reported the food getting stuck in his throat. He had been treated for aspiration pneumonia once. A year later, he noticed slowly progressive limb weakness affecting his hands and proximal lower limbs, described as difficulty holding a tablet at church, frequently dropping objects from his hands, and difficulty with standing up from a seated position. More recently, he started experiencing dyspnea on exertion and mild orthopnea. He occasionally experienced blurry vision without diplopia, mild head drop, and hoarseness of voice, mainly towards the end of the day or when he was tired. He was diagnosed with seronegative myasthenia gravis at a local facility, with negative acetylcholine receptor, muscle-specific kinase, and low-density lipoprotein receptor-related protein 4 antibodies. His medical and social history were otherwise unremarkable. The patient's father was French Canadian. The patient also had Native American and African American ancestry. There was no family history of myopathy or any neuromuscular disorder. Neurologic examination was significant for moderate bilateral ptosis, bilateral ophthalmoparesis with limited upward gaze and to a lesser extent horizontal gaze (both eye abduction and adduction), mild weakness of both upper and lower facial muscles, moderate weakness of the proximal lower extremities most prominent at the hip abductors (Medical Research Council [MRC] grade 3 to 4-/5), and mild (MRC grade 4) weakness of finger extensors and intrinsic hand muscles. He had no demonstrable fatigable weakness on examination in any of the affected muscles. He had a mildly waddling gait and absent ankle jerks bilaterally. Sensory and coordination evaluations were unremarkable.

\section{Questions for consideration:}

1. What is the localization for the patient's symptoms and examination findings?

2. What investigations would you perform?

\section{GO TO SECTION 2}




\section{Section 2}

The pattern of weakness manifesting with bilateral symmetric distal upper and proximal lower limb weakness, without any upper motor neuron signs, and the presence of marked bilateral ptosis would be unusual for a CNS etiology and indicates a peripheral nervous system disorder. While any defect along the motor pathways can result in dysphagia and dyspnea, especially at advanced stages, the predominant ptosis and extraocular muscle involvement are more suggestive of a neuromuscular transmission defect or a myopathy, rather than a motor neuropathy or neuronopathy. With no evidence of demonstrable fatigability on examination, the patient-reported fluctuation of the weakness with diurnal variation is not necessarily specific for a neuromuscular transmission defect, and hence a myopathy should be considered. Furthermore, patients with myopathy can have a component of muscle fatigue. It is noteworthy that the presence of ophthalmoparesis without diplopia would be unusual for myasthenia gravis, and is more likely to be due to a slowly developing process such as a hereditary myopathy. The slow progression rate and the clinical phenotype with ptosis and ophthalmoparesis would make an acquired myopathy, such as an inflammatory myopathy, less likely.

To further refine the localization, electrodiagnostic testing was performed. Upper and lower limbs and sensory and motor nerve conduction studies were normal except for a borderline low sural sensory nerve action potential amplitude of $6 \mu \mathrm{V}$ (normal $>6 \mu \mathrm{V})$. Two- $\mathrm{Hz}$ repetitive nerve stimulation of the facial, spinal accessory, and ulnar nerves, at rest and after exercise, were normal. Needle EMG showed early recruitment of short duration, low-amplitude motor unit potentials, often with increased phases and turns, in proximal and distal, upper, and lower limb muscles as well as in cranial muscles. Fibrillation potentials were present in cranial muscles, proximal upper limb muscles, and tibialis anterior. These electrodiagnostic findings were consistent with a myopathic process.

Laboratory workup was remarkable for an elevated creatine kinase of 550 (normal 52-336 U/L). Blood tests including liver function, renal function, thyroid-stimulating hormone, and lactate level were normal. Myositis autoantibody panel and acetylcholine receptor binding antibodies were normal as well. A video swallow study showed moderate oropharyngeal dysphagia with marked prominence of the cricopharyngeus muscle (figure 1). Pulmonary function tests showed a normal vital capacity, but a decreased maximal expiratory pressure. Overnight oximetry showed evidence of mild sleep-related disordered breathing.

\section{Question for consideration:}

1. Based on these results, what types of myopathy would you consider on the top of your differential?

Figure 1 Barium video-swallow evaluation

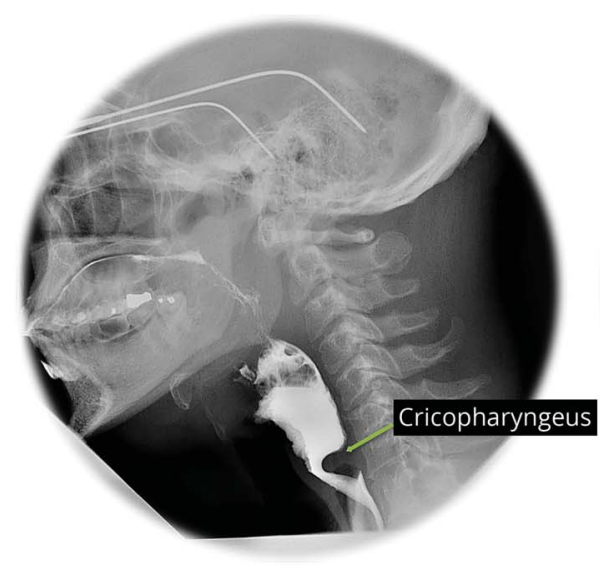

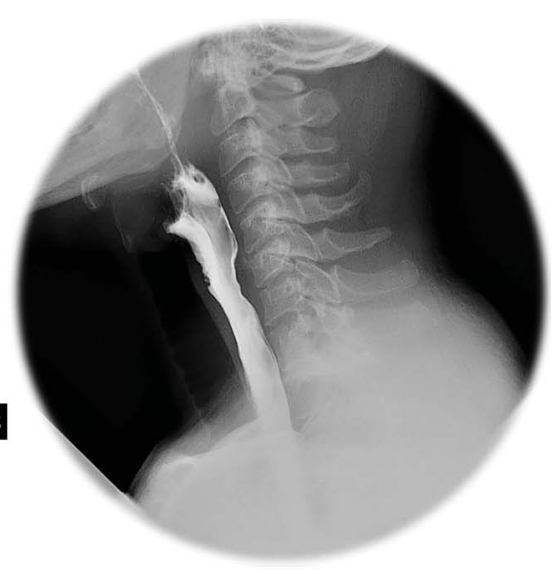

Barium video-swallow showing significant prominence of the cricopharyngeus, which covers well over half of the luminal diameter (left), markedly improved after cricopharyngeal myotomy (right).

\section{GO TO SECTION 3}




\section{Section 3}

The electrodiagnostic testing confirmed the presence of a myopathy. The slowly progressive clinical course is suggestive of a hereditary myopathy. With the absence of other affected family members, the mode of inheritance remains unclear. While the pattern of weakness predominantly affecting hip girdle muscle can be seen with a wide spectrum of hereditary myopathies, the marked ptosis and ophthalmoparesis help narrow down the differential diagnosis to include oculopharyngeal muscular dystrophy (OPMD), mitochondrial myopathy, or a congenital myopathy. ${ }^{1}$ Among the congenital myopathies, RYR1-related myopathy can have prominent ptosis with or without ophthalmoplegia. ${ }^{2,3}$ In its classical form, RYR1-related myopathy is usually associated with central core disease on muscle histopathology and is inherited in an autosomal dominant pattern. However, autosomal recessive forms, which can be associated with multiminicore disease or centronuclear myohistopathology, can have more prominent ptosis. Interestingly, mutations in other genes associated with a centronuclear myopathy, such as MTM and DNM2, and congenital fiber type disproportion or a cap myopathy such as TPM2 or TPM3, can also cause a myopathy with neuromuscular transmission defect, associated with prominent ptosis with or without ophthalmoparesis. ${ }^{4-6}$ On the other hand, marked ptosis is relatively common in congenital myasthenic syndromes, and the presence of a myopathy with fibrillation potentials does not rule out such conditions, as many of the genes such as ALG2, ALG14, DPAGT1, GMPPB, PLEC, and GFPT1 can cause both a myasthenic syndrome and a myopathy. ${ }^{7}$ Furthermore, congenital myasthenic syndromes can rarely present with normal repetitive nerve stimulation. Based on the clinical phenotype with the prominent dysphagia and the markedly prominent cricopharyngeus muscle, in a patient of French Canadian-Native American background, we had strong suspicion for OPMD. Subsequently, the patient was tested for this condition but had no GCN repeat expansions in the polyadenine binding protein nuclear (PABPN1) gene.

\section{Questions for consideration:}

1. Is the possibility of OPMD ruled out?

2. What will be your next step?

GO TO SECTION 4 


\section{Section 4}

OPMD is an autosomal dominant condition secondary to expansion of a GCN trinucleotide repeat in exon 1 of the PABPN1 gene. However, point mutations have also been reported and had to be ruled out. ${ }^{8}$ Therefore, sequencing of the PABPN1 gene was performed in our patient but showed no mutations. At this point, we decided to pursue a left gluteus medius muscle biopsy to guide further genetic testing. It showed frequent ragged-red, raggedblue, and cytochrome $C$ oxidase-negative fibers with rare atrophic and regenerating fibers indicating a mitochondrial myopathy (figure 2). Subsequently, we performed mitochondrial genome analysis on the muscle specimen, which was normal with no mutations or deletions. Thereafter, we obtained a mitochondrial nuclear gene panel, which showed 2 mutations in polymerase $\gamma$ (POLG): (1) p.Arg1096His (c.3287G >A), an established pathogenic mutation; and (2) p.Arg953Cys (c.2857C >T), a likely pathogenic mutation. The patient's asymptomatic mother and brother both were tested and carried the $p$.Arg1096His mutation, indicating that the 2 mutations were heteroallelic.

\section{Discussion}

Mitochondrial myopathies can be caused by mutations in either mitochondrial DNA (mtDNA) or nuclear genes. Mutations in mtDNA may affect only a proportion of the multiple copies of mtDNA within each cell, and result in the presence of both normal and mutant mtDNA, a phenomenon known as heteroplasmy. The degree of heteroplasmy can vary between cells in the same tissue or organ, between different organs within the same individual, and also between individuals in the same family. Therefore, manifestations of a mitochondrial disorder reflect tissue-specific mutation load, and hence it is essential that analysis of mtDNA is performed from the muscle tissue when myopathy is suspected. Progressive external ophthalmoplegia (PEO) with or without associated limb myopathy can be seen with both primary mitochondrial and nuclear DNA defects. Primary mtDNA defects can be due to point mutations or a single large mtDNA deletion. Among single large-deletion disorders, patients can have a spectrum of clinical manifestations ranging from a pure myopathic presentation (i.e., pure PEO) to multisystem involvement as seen in Kearns-Sayre syndrome, with associated pigmentary retinopathy, hearing loss, short stature, or cardiac conduction abnormalities. ${ }^{9}$ A growing list of nuclear genes encoding proteins involved in maintenance, transcription, or translation of mtDNA have been reported in mitochondrial disorders, including POLG. POLG encodes the catalytic subunit of POLG, the sole DNA polymerase enzyme responsible for mtDNA replication and repair. Mutations in POLG can be associated with a wide spectrum of clinical manifestations ranging from encephalopathy and epilepsy to sensory ataxia and myopathy, presenting from neonatal period to late adult life. ${ }^{10,11}$ From a myopathy standpoint, patients may present with $\mathrm{PEO}$ with or without an associated limb myopathy, in an autosomal dominant or recessive pattern of inheritance. Patients may also present with limb weakness without extraocular muscle involvement. ${ }^{12}$ The 2 mutations detected in our patient have been described in association with chronic progressive external ophthalmoplegia. ${ }^{13,14}$

The cricopharyngeus muscle is an essential part of the upper esophageal sphincter and its relaxation allows forward passage of food bolus during the oropharyngeal phase of swallowing. Failure to relax or early closure can cause dysphagia symptoms and imaging studies may show a posterior indentation on the pharyngeal wall, described as "prominent cricopharyngeus" or a cricopharyngeal bar. It is noteworthy that this can also be an asymptomatic incidental finding associated with aging. Nevertheless, this is not a specific finding for OPMD as it can also be seen in myotonic dystrophy and inflammatory myopathies, especially inclusion body myositis, sometimes requiring dilation or

Figure 2 Muscle biopsy findings

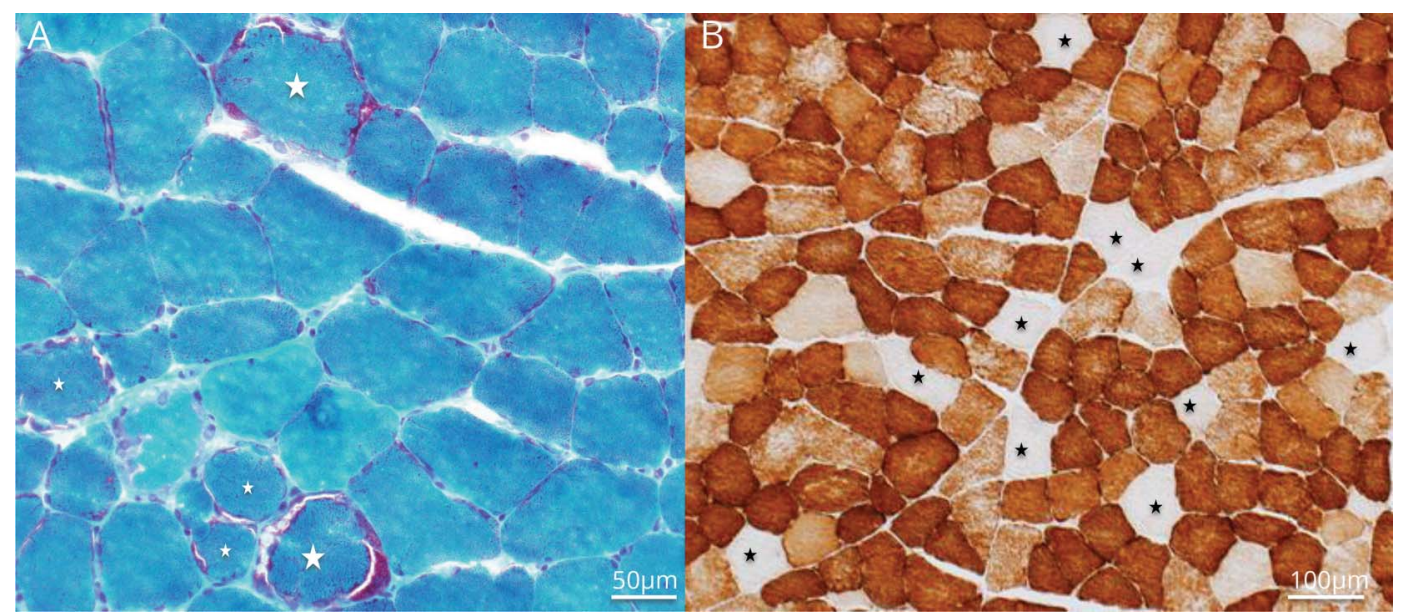

Left gluteus medius muscle biopsy. (A) Modified Gomori trichrome-stained section showing scattered ragged-red fibers, most prominent in the fibers indicated by a star. (B) Cytochrome C oxidase-stained section showing multiple fibers (stars) with absent enzyme reactivity (cytochrome $C$ oxidase-negative fibers). 


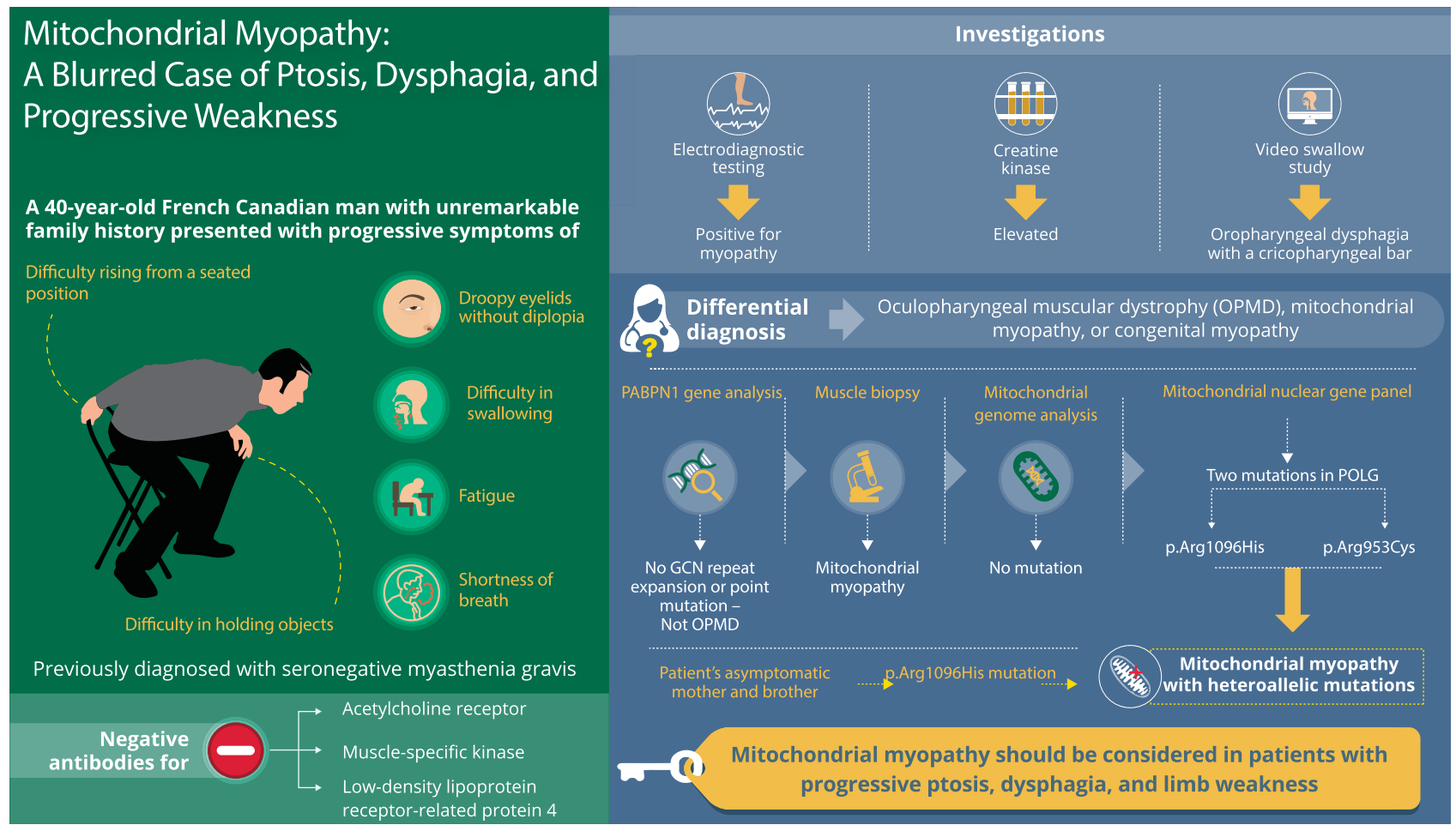

Copyright (c) 2020 American Academy of Neurology

Neurology

myotomy. Prominent cricopharyngeus or cricopharyngeal achalasia has been rarely reported in mitochondrial myopathies including mtDNA deletion syndrome. ${ }^{15,16}$

We reported a case of progressive ptosis, dysphagia, and limb weakness, with marked cricopharyngeus prominence, due to 2 heterozygous mutations in POLG. Even though OPMD is more common in people with French Canadian origin, alternative etiologies, such as a mitochondrial myopathy, may present with similar phenotype, and should also be considered.

\section{Study funding}

No targeted funding reported.

\section{Disclosure}

The authors report no disclosures relevant to the manuscript. Go to Neurology.org/ $\mathrm{N}$ for full disclosures.

\section{Appendix Authors}

\begin{tabular}{|c|c|c|}
\hline Name & Location & Contribution \\
\hline $\begin{array}{l}\text { Pritikanta } \\
\text { Paul, MD }\end{array}$ & $\begin{array}{l}\text { Department of Neurology, } \\
\text { Mayo Clinic, Rochester, } \\
\text { MN }\end{array}$ & $\begin{array}{l}\text { Study concept and design, } \\
\text { acquisition of data, drafting } \\
\text { of the manuscript, critical } \\
\text { revision of the manuscript } \\
\text { for important intellectual } \\
\text { content }\end{array}$ \\
\hline $\begin{array}{l}\text { Reem } \\
\text { Alhammad, } \\
\text { MD }\end{array}$ & $\begin{array}{l}\text { Department of Neurology, } \\
\text { King Saud University, } \\
\text { Riyadh, Saudi Arabia }\end{array}$ & $\begin{array}{l}\text { Study concept and design, } \\
\text { critical revision of the } \\
\text { manuscript for important } \\
\text { intellectual content }\end{array}$ \\
\hline
\end{tabular}

Appendix (continued)

\begin{tabular}{lll}
\hline Name & Location & Contribution \\
\hline $\begin{array}{lll}\text { Elie Naddaf, } \\
\text { MD }\end{array}$ & $\begin{array}{l}\text { Department of Neurology, } \\
\text { Mayo Clinic, Rochester, }\end{array}$ & $\begin{array}{l}\text { Study concept and design, } \\
\text { drafting of the manuscript, } \\
\text { critical revision of the } \\
\text { manuscript for important } \\
\text { intellectual content, study } \\
\text { supervision }\end{array}$ \\
& & \\
\end{tabular}

\section{References}

1. Barohn RJ, Dimachkie MM, Jackson CE. A pattern recognition approach to patients with a suspected myopathy. Neurol Clin 2014;32:569.

2. Lawal TA, Todd JJ, Meilleur KG. Ryanodine receptor 1-related myopathies: diagnostic and therapeutic approaches. Neurotherapeutics 2018;15:885-899.

3. Illingworth MA, Main M, Pitt M, et al. RYR1-related congenital myopathy with fatigable weakness, responding to pyridostigmine. Neuromuscul Disord 2014;24: $707-712$.

4. Tajsharghi H, Ohlsson M, Lindberg C, Oldfors A. Congenital myopathy with nemaline rods and cap structures caused by a mutation in the $\beta$-tropomyosin gene (TPM2). Arch Neurol 2007;64:1334-1338.

5. Munot P, Lashley D, Jungbluth $\mathrm{H}$, et al. Congenital fibre type disproportion associated with mutations in the tropomyosin 3 (TPM3) gene mimicking congenital myasthenia. Neuromuscul Disord 2010;20:796-800.

6. Jungbluth H, Wallgren-Pettersson C, Laporte J. Centronuclear (myotubular) myopathy. Orphanet J Rare Dis 2008;3:26.

7. Nicolau S, Kao JC, Liewluck T. Trouble at the junction: when myopathy and myasthenia overlap. Muscle Nerve 2019;60:648-657.

8. Robinson DO, Wills AJ, Hammans SR, Read SP, Sillibourne J. Oculopharyngeal muscular dystrophy: a point mutation which mimics the effect of the PABPN1 gene triplet repeat expansion mutation. J Med Genet 2006;43:e23.

9. Mancuso M, Orsucci D, Angelini C, et al. Redefining phenotypes associated with mitochondrial DNA single deletion. J Neurol 2015;262:1301-1309.

10. Horvath R, Hudson G, Ferrari G, et al. Phenotypic spectrum associated with mutations of the mitochondrial polymerase $\gamma$ gene. Brain 2006;129:1674-1684.

11. Milone M, Benarroch EE, Wong LJ. POLG-related disorders. Neurology 2011;77: 1847.

12. Giordano C, Pichiorri F, Blakely EL, et al. Isolated distal myopathy of the upper limbs associated with mitochondrial DNA depletion and polymerase $\gamma$ mutations. Arch Neurol 2010;67:1144-1146. 
13. Schulte C, Synofzik M, Gasser T, Schöls L. Ataxia with ophthalmoplegia or sensory neuropathy is frequently caused by POLG mutations. Neurology 2009;73:898.

14. Luoma P, Melberg A, Rinne JO, et al. Parkinsonism, premature menopause, and mitochondrial DNA polymerase $\gamma$ mutations: clinical and molecular genetic study. Lancet 2004;364:875-882.
15. Vogel AP, Rommel N, Oettinger A, et al. Speech and swallowing abnormalities in adults with POLG associated ataxia (POLG-A). Mitochondrion 2017;37:1-7.

16. Kornblum C, Broicher R, Walther E, et al. Cricopharyngeal achalasia is a common cause of dysphagia in patients with mtDNA deletions. Neurology 2001;56: 1409 .

\section{Neurology ${ }^{\circledR}$ Online CME Program}

Earn CME while reading Neurology. This program is available only to online Neurology subscribers. Read the articles marked CME, go to Neurology.org, and click on CME. This will provide all of the information necessary to get started. The American Academy of Neurology (AAN) is accredited by the Accreditation Council for Continuing Medical Education (ACCME) to sponsor continuing medical education for physicians. Neurology is planned and produced in accordance with the ACCME Essentials. For more information, contact AAN Member Services at 800-879-1960.

\section{Call for Voices: Lived Experiences}

The Editors of the Neurology specialty site Equity, Diversity, \& Inclusion encourage you to submit short first-person accounts (1,000 words or less) of experiences lived within the realm of equity, diversity, and inclusion (EDI) with the goal of informing and enlightening our community on these critical issues. Some topics to consider include, but are not limited to:

- Descriptions of personal experiences that shaped your views of EDI.

- Reflections on the intersection between personal identity and career.

- Discussions at the intersection of EDI and neurology patient care, research, education, advocacy, or policy.

Submit your contributions to journal@neurology.org and include "Voices Submission" in the subject line.

\section{Disputes \& Debates: Rapid online correspondence}

The editors encourage comments on recent articles through Disputes \& Debates:

Access an article at Neurology.org/ $N$ and click on "MAKE COMMENT" beneath the article header. Responses will be posted as rapidly as possible.

Before submitting a comment to Disputes \& Debates, remember the following:

- Disputes \& Debates is restricted to comments about articles published in Neurology within the last 8 weeks

- Read previously posted comments; redundant comments will not be posted

- Your submission must be 200 words or less and have a maximum of 5 references; the first reference must be the article on which you are commenting

- You can include a maximum of 5 authors (including yourself) 


\section{Neurology}

\section{Clinical Reasoning: Bilateral ptosis, dysphagia, and progressive weakness in a patient of French-Canadian background}

Pritikanta Paul, Reem Alhammad and Elie Naddaf

Neurology 2020;95;933-938 Published Online before print October 12, 2020

DOI 10.1212/WNL.0000000000010613

This information is current as of October 12, 2020

\section{Updated Information \&} Services

References

Subspecialty Collections

Permissions \& Licensing

Reprints including high resolution figures, can be found at: http://n.neurology.org/content/95/20/933.full

This article cites 16 articles, 4 of which you can access for free at: http://n.neurology.org/content/95/20/933.full\#ref-list-1

This article, along with others on similar topics, appears in the following collection(s):

All Clinical Neurology

http://n.neurology.org/cgi/collection/all_clinical_neurology All Neuromuscular Disease

http://n.neurology.org/cgi/collection/all_neuromuscular_disease Mitochondrial disorders

http://n.neurology.org/cgi/collection/mitochondrial_disorders Muscle disease

http://n.neurology.org/cgi/collection/muscle_disease

Information about reproducing this article in parts (figures,tables) or in its entirety can be found online at:

http://www.neurology.org/about/about_the_journal\#permissions

Information about ordering reprints can be found online:

http://n.neurology.org/subscribers/advertise

Neurology ${ }^{\circledR}$ is the official journal of the American Academy of Neurology. Published continuously since 1951, it is now a weekly with 48 issues per year. Copyright () 2020 American Academy of Neurology. All rights reserved. Print ISSN: 0028-3878. Online ISSN: 1526-632X.

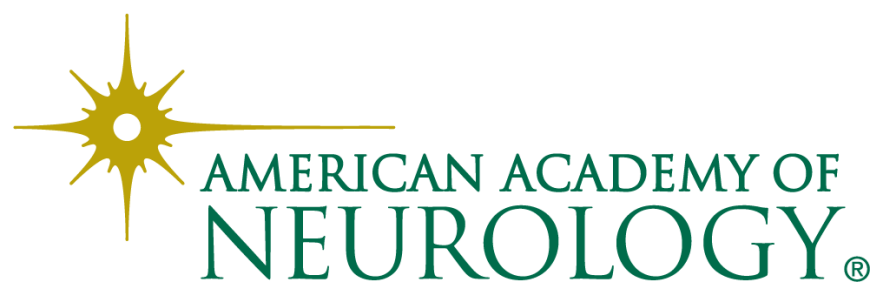

